\title{
The USGT Method for Suspender Tensioning of Self-Anchored Suspension Bridges
}

\author{
Hongmei Tan (D), ${ }^{1,2}$ Zhujian Hou, ${ }^{2}$ Zhou Qiu, ${ }^{2}$ Junlin Ji, $^{3}$ and Dahan Chen ${ }^{4}$ \\ ${ }^{1}$ Mountain Bridge and Materials Engineering Research Center of Ministry of Education, Chongqing Jiaotong University, \\ Chongqing 400074, China \\ ${ }^{2}$ State Key Laboratory of Mountain Bridge and Tunnel Engineering, Chongqing Jiaotong University, Chongqing 400074, China \\ ${ }^{3}$ CMCU Engineering Co., Ltd., Chongqing 400074, China \\ ${ }^{4}$ Xiamen Municipal Engineering Design Institute Co., Ltd., Xiamen, China
}

Correspondence should be addressed to Hongmei Tan; hmtan@cqjtu.edu.cn

Received 25 December 2020; Revised 12 April 2021; Accepted 6 May 2021; Published 25 May 2021

Academic Editor: Quoc-Bao Bui

Copyright (C) 2021 Hongmei Tan et al. This is an open access article distributed under the Creative Commons Attribution License, which permits unrestricted use, distribution, and reproduction in any medium, provided the original work is properly cited.

Unlike earth-anchored suspension bridges, self-anchored suspension bridges (SASBs) involve a special construction stage, namely, suspender tensioning, in which the tensioning force and sequence are crucial and complicated. Against this background, an example bridge A, a SASB with a steel-concrete composite beam, is introduced in detail. Using MIDAS finite element software, a suspender tensioning scheme is formulated based on a combination method of the unstrained state method and graded tension method (the USGT method), in which a suspender is tensioned according to its unstrained length. By analyzing the bending moment change of the beam and deflection of the main cable throughout the entire construction process, a "high-to-low" suspender tensioning sequence is proposed that also involves symmetrical tensioning from the main towers to the midspan or the anchor positions. In the optimized construction process, the deviation and stress of the main towers are controlled well, thereby ensuring the safety of the main beam and main towers in the construction process.

\section{Introduction}

In recent years, due to many advantages, cable-stayed bridges have often constructed in the medium and long span $[1,2]$. As early as in the 1800s, two engineers, Josef Langer in Austria and Charles Bender in America, independently conceived of the SASB [3]. In 1870, in Poland, Langer built a small SASB that carried train traffic, and SASBs became common in Germany in the early 1900s. In 1915, the Deutz Suspension Bridge with a main span of $185 \mathrm{~m}$, the first largescale SASB in Germany, was built crossing the Rhine. This innovative form influenced the design of other bridges, specifically, the three bridges crossing the Allegheny River in America and the smaller Kiyosu Bridge in Japan [3]. Since 1990, when a famous monocable SASB, the Konohana Bridge in Osaka with its only main cable and inclined hangers aligned along the center of the roadway [3], was completed, more and more SASBs have been built around the world [4-7].
Since using a different anchoring system, where main cables in SASBs are anchored to stiffening girders instead of massive earth anchors, the construction procedure is also considerably different between SASBs and earth-anchored suspension bridges [8]. For the latter, the main cables and suspenders (or hangers) are installed before stiffening girders, while for most of SASBs, however, stiffening girders must be erected prior to the main cables $[4,9,10]$. Therefore, the final construction process involves system transformation program when the dead loads are transferred from the temporary piers to the main cables after installing suspenders. Therefore, the suspender tension value and process, which will deeply influence internal force and alignment of the completion stage, should be analyzed in depth.

Throughout the entire SASB construction process, installing and tensioning the suspenders are the most difficult construction process regarding the technology that is required, and the construction accuracy is very sensitive to 
relevant parameters. The suspender tensioning is influenced by many parameters, such as (i) the weight of the main girder, (ii) the structural stiffness, and (iii) the length of the main cables. The actual values of these parameters deviate inevitably from the theoretical values, thereby causing those values of the suspenders to deviate from the designed values under the target conditions [4].

Currently, the main theoretical methods used to guide the installing and tensioning of suspenders are the alternating forward tension method, the influence matrix method, and the unstrained state method (USM) [11]. Each of these methods has its own characteristics and can accurately achieve the design cable force. However, in practical engineering, the suspenders often need repeated tensioning to achieve the design state.

The aim of the present study was to determine a reasonable and efficient suspender installation procedure based on the USGT method (a combination method of the unstrained state method and graded tension method) for the construction research of a self-suspension bridge, bridge A. For this purpose, a finite element (FE) model was used to perform a series of backward and forward interactive nonlinear construction step analyses.

\section{Example: Bridge A}

Bridge A (see Figures 1-4) is an SASB with symmetric double towers and three suspended spans consisting of a $266 \mathrm{~m}$ main span and two $100 \mathrm{~m}$ side spans. It has $27.5 \mathrm{~m}$ wide steel-concrete composite box girders (as in Figure 1), and the stiffening girder (as in Figure 2) is erected by means of incremental launching. The ratio of cable sag to its span (also called sag-span ratio) is $1 / 10$ at the midspan, and the towers (as in Figure 3) are made of prestressed concrete (C50) and shaped like an "A" transversally. Other basic parameters of this bridge are listed in Table 1. Each main cable is made of 37 prefabricated parallel wire strands (as in Figure 3), each of which consists of $127 \Phi 5 \mathrm{~mm}$ highstrength galvanized steel wires, forming a regular hexagon in cross section. Similarly, suspenders (as in Figure 4) are also made of high-strength galvanized steel wires. The stiffening girder is constructed using the incremental launching method.

\section{Unstrained State Method}

For bridges, especially those with large spans, construction control is very necessary. Construction control refers to the monitoring of the main structural parameters, including the stress, displacement, and stability of the structure. This is done to ensure that these parameters remain within reasonable ranges throughout the process and that the structure is safe until the completion state. In actual construction control, each important parameter is measured and then applied to a computational model for correction in order to correct any construction deviation. This is done so that each construction stage can proceed according to the original plan and so that the alignment and internal stress state of the design can be achieved.
There are many methods for bridge construction control, one being the USM $[12,13]$. This method consists of two stages. In the first stage, the unstrained lengths of both cables and their segments are determined to find each cable initial configuration and the whole bridge structures [13-15]. For this purpose, the USM involves using the unstrained lengths of all elements, for example, cable segments, determined from the completion state. Once the unstrained element lengths are derived, they are treated as constants or some known values. So, by ensuring these remain constant, a nonlinear FE analysis using Newton iteration is performed in the second stage of the USM.

For an SASB in the suspender tensioning stage, the value of the pull-out length or pull-back length of each suspender is calculated based on its unstrained length, along with its initial tension being adjusted accordingly. In this way, the final internal force and displacement of the structure have nothing to do with the construction process. It also avoids the change of cable force caused by the load change of temporary facilities and the temperature difference effect of sunshine.

\section{Main Characteristics of the Unstrained State Method}

Used in the construction of many bridges (e.g., the Second Wuhan Yangtze River Bridge), the USM has produced satisfactory results for both suspension and cable-stayed bridges. In summary, the calculation process of the USM is contrary to the real construction process. First, the completion state is chosen as the initial state. From the stress state and geometric alignment of this state, the unstrained length of each cable segment or each suspender is determined. Then, according to the principle mentioned above that the unstrained length remains constant throughout the whole construction stage, reasonable suspender forces are determined in any intermediate stage of the construction process, even though there are many intermediate stages including the complex system transformation. Besides, the internal forces and displacements in the completion state, which is unrelated to the construction process, are determined once the unstrained lengths of the suspenders are determined. Finally, the influence of the construction load and temperature change on the deflection and stress state of the final stage can be neutralized by adjusting the suspender length.

\section{Unstrained Length Calculation of the Cable}

The theory for calculating cable unstrained length is based on the following hypotheses. (1) The cables (and suspenders) are so flexible that they cannot resist compression or bending. (2) The cable stress is much lower than its yield strength; accordingly, the stress-strain relationship conforms to Hooke's law. (3) The area change of the cross section caused by length elongation or shortening is negligible. (4) The weight of the stiffening girder is undertaken by the main cables. The unstrained cable length in a 


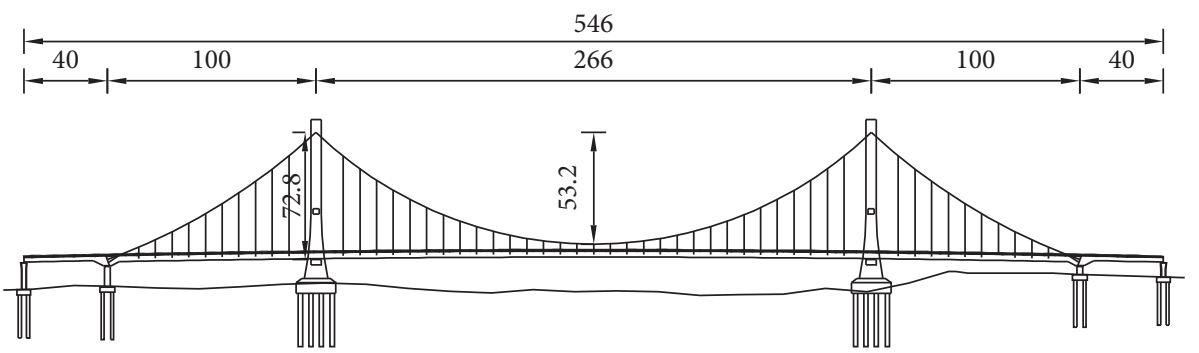

FIgURE 1: Overall layout of bridge A (dimensions are in $\mathrm{m}$ ).

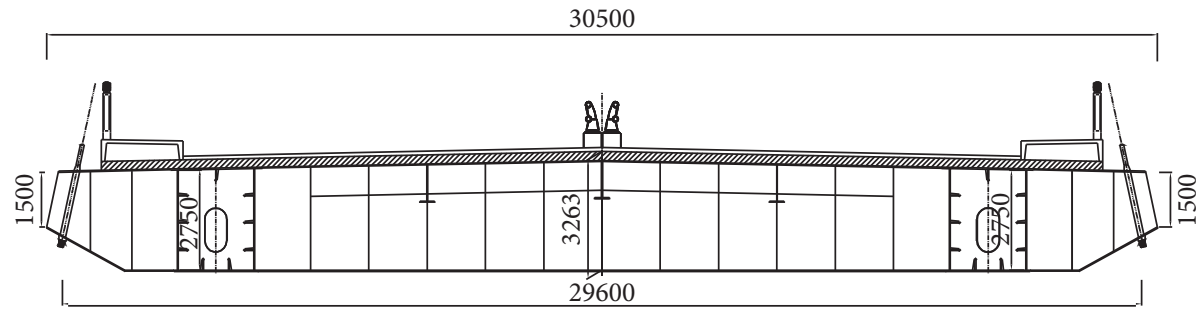

FIgURE 2: Cross section of the stiffening girder (dimensions are in $\mathrm{mm}$ ).

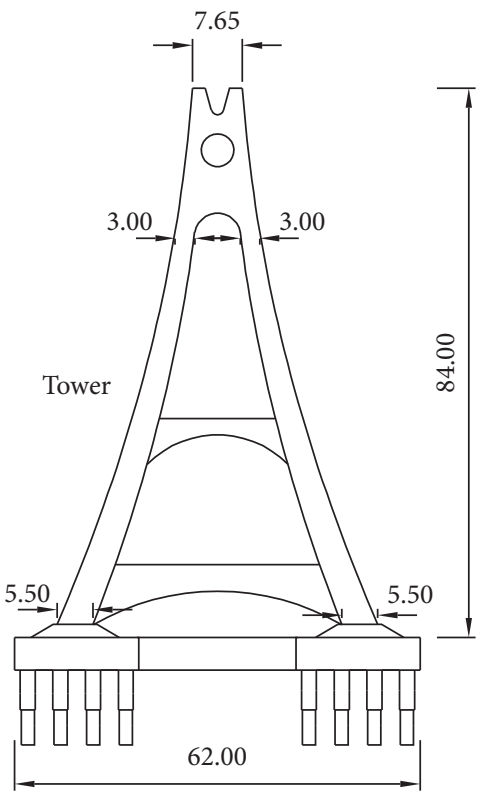

Figure 3: Tower and cable (dimensions are in $\mathrm{m}$ ).

suspension bridge is approximately calculated by the following three steps.

Based on the catenary (or parabolic) equation of cable alignment $[14,16]$, the strained length $S$ and the unstrained length $S_{0}$ of a cable can be obtained when the self-weight, sag, and span of the cable are all given.

Then, when the stiffening girder alignment in the completion state and the geometric alignment of the main cables (or so-called shape finding) have been solved, the strained length of each suspender is obtained. Then, subtracting the elastic elongation gives the unstrained length.

For the influence of temperature change, it will cause the cable or suspenders to become longer or shorter. The values of elongation or shortening have a relation with thermal expansion coefficient and temperature change. Anyway, the unstressed length still remains unchanged. So, the effect of the overall uniform temperature change is solved by changing the cable/suspender stressed length.

\section{Application of the Unstrained State Method}

When analyzing a real bridge, forward analysis, backward analysis, and the influence matrix method can be combined to calculate internal force and deflection of each construction stage of a bridge, ensure the safety of construction, and achieve the ideal stress state and geometric alignment in the completion stage. The USM can be used in the analysis of the suspension bridge construction. The unstrained parameter values of the components, such as cables and suspenders, are obtained based on the completion stage in design, and then it is ensured that the unstrained length during the manufacturing process is consistent with the above values. In the final stage, it is ensured that the relevant parameters of the completion state are consistent with the design expectation.

Taking bridge A as an example (as shown in Figure 5), the main towers and temporary piers are installed first. Then, the steel box girder, in which segments are temporarily connected by hinge joints, is incrementally launched into place, and immediately, the main cables and suspenders (as shown in Figure 4) are drawn. Finally, the suspenders are tensioned. The process of suspender tensioning is monitored and controlled according to the unstrained length determined by the previous calculations, that is, using the USM to monitor and control the process of girder jacking up and jacking down by marking the position of the designed unstrained length of suspenders. The unstrained length remains unchanged during the entire construction process. 
TABLe 1: Material and cross-sectional properties of bridge A.

\begin{tabular}{|c|c|c|c|c|c|c|c|}
\hline Structural member & $E(\mathrm{GPa})$ & $G(\mathrm{GPa})$ & Density $\rho\left(\mathrm{kg} / \mathrm{m}^{3}\right)$ & Area $A\left(\mathrm{~m}^{2}\right)$ & $I_{y y}\left(\mathrm{~m}^{4}\right)$ & $I_{z z}\left(\mathrm{~m}^{4}\right)$ & $I_{x x}\left(\mathrm{~m}^{4}\right)$ \\
\hline Cable & 195 & - & 7850 & 0.092265 & & & \\
\hline Suspender & 195 & - & 7850 & 0.021775 & & & \\
\hline Stiffening girder & 34.5 & 26.2 & 2600 & 1.929 & 2.1406 & 179.836 & 0.07204 \\
\hline Upper part of the tower & 34.5 & 26.2 & 2600 & 10.1598 & 26.7475 & 9.88972 & 25.0849 \\
\hline Middle part of the tower & 34.5 & 26.2 & 2600 & 13.9478 & 37.4151 & 26.6208 & 52.8699 \\
\hline Lower part of the tower & 34.5 & 26.2 & 2600 & 32.5598 & 418.811 & 129.014 & 326.354 \\
\hline
\end{tabular}

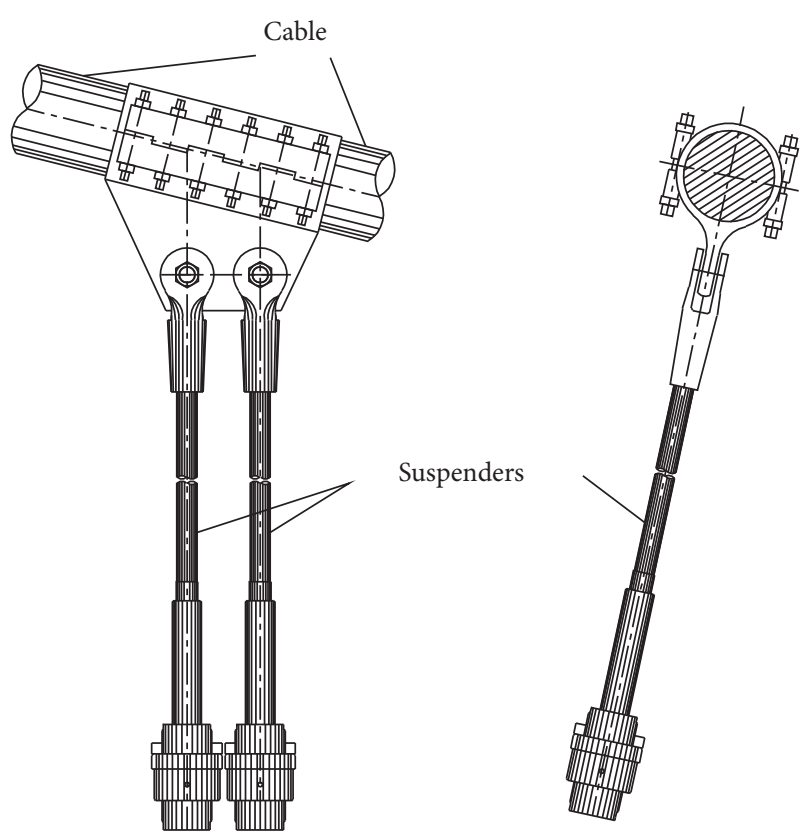

FIGURE 4: Suspenders.

So, once the unstrained parameter values of the bridge elements in the expected completion state have been determined, the stress and displacement states of the whole bridge in the completion stage are unrelated to the construction process and method. Generally, in the design calculations and construction control of a suspension bridge, the unstrained lengths are key parameters, and the USM is applied based on adjusting the unstrained parameters.

When hauling strands of the cable, the USM can also be used for construction analysis, which is studied in another paper [14].

\section{The USGT Method to Analyze the Tensioning Sequence of Bridge A Suspenders}

When using the USM to tension suspenders initially according to their predetermined unstrained lengths, the maximum suspender tension may reach an unexpectedly high level and exceed the design force.

A geometrically nonlinear analysis of bridge $\mathrm{A}$ is preferable for formulating a reasonable tensioning sequence and tensioning grade, and this is done using MIDAS FE software. The main cables and the suspenders are simulated by cable elements, while the stiffening girder and

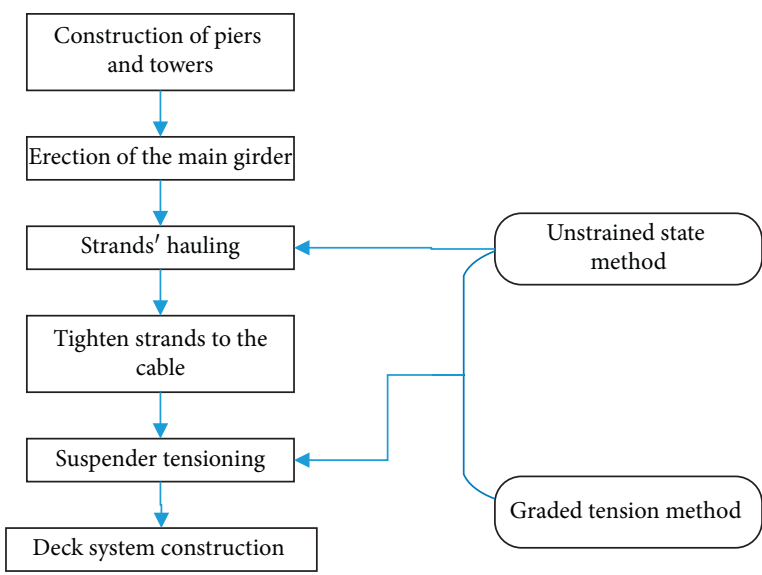

FIgURE 5: Unstrained state method applied in the construction of self-anchored suspension bridges.

the towers are both simulated using beam elements. Sections of the concrete-steel composite stiffening girder are simulated by the joint section, and towers are with a threedimensional variable section. The supports are rigid in that the vertical, lateral, and torsional freedoms and the lateral bending freedom of the main beam are constrained. The longitudinal displacements at the top of towers are very important; once they exceed their allowable value, the main saddles should be pushed. So, in the FEM, the horizontal displacement constraint between the cable and towers is released.

The FE model of whole bridge A is shown in Figure 6, which includes bearing the gravities of cables, stiffening girder, and accessory components.

There are various tensioning sequences for SASB suspenders, each of which influences the whole structure differently. The following are the three tensioning sequences that tend to be used currently: (i) from high to low-from the suspenders near the towers to those at the midspan of the main span and splay saddle positions of the side spans; (ii) from low to high-contrary to (i), from short suspenders to long ones; (iii) from the middle to the sides-for a side span, from the suspenders at the midspan to those near the anchor position and tower and for the main span, from the suspenders in $1 \mathrm{~L} / 4$ of span and $3 \mathrm{~L} / 4$ of span to those near the towers and the midspan.

In tensioning sequence (ii), the previously tensioned suspenders are affected by the subsequent ones, resulting in increased or decreased suspender forces. The midspan suspenders are most vulnerable because they are tensioned first. Therefore, if the tension of the first tensioned 


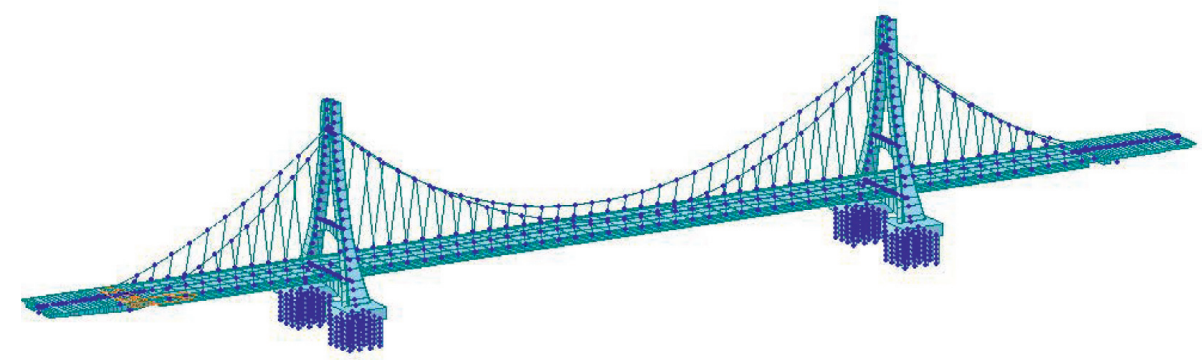

Figure 6: Finite element model of bridge A.

suspender cable is relatively large, then the cable force may exceed the allowable maximum in the later tensioning. Consequently, the subsequent tensioning scheme must be adjusted, thereby complicating the entire tensioning process and making it difficult to achieve the expected result. The other two tensioning sequences are also prone to this problem.

To solve this problem, the most commonly used and adaptive principle in construction control can be used, namely, the graded tension method (GTM), in which a small cable force is applied to the tensioned suspender to fix it. During the subsequent tensioning process, by means of large displacement deformations of the main cables, those suspenders that were not tensioned in place before can be adjusted adaptively to achieve a reasonable suspender force.

The suspender is tensioned in three stages. (1) In the first stage, small forces are applied to the tensioned suspenders to fix them. The suspender forces are also small because of the small changes in the geometric alignments of the main cables. The main controlling factors are the bending moments of the towers and the stiffening girder. (2) In the second stage, during the subsequent tensioning process, those suspenders that were not tensioned in place before can be adjusted adaptively to achieve suitable suspender forces. In this stage, the purpose of tensioning a suspender is to bring the actual force as close as possible to its value in the completion state. Therefore, the main controlling factor is the difference between the two. (3) In the third stage, those suspenders whose tension is either too low or too high are corrected by either interval or alternate tensioning, and finally, reasonable suspender forces are approached.

In their specific implementations, the three common methods of suspender force grading are as follows. (1) The ideal tension $P$ of any suspender is divided into five grades, namely, $0.2 P, 0.4 P, 0.6 P, 0.8 P$, and $P$. (2) First, all suspenders are tensioned for the first time (known as installation tensioning) to approximately $25 \%$ of the ideal suspender tension $P$. Then, the corresponding suspenders are tensioned separately to $50 \%, 75 \%$, and $100 \%$ of the ideal suspender tension $P$. (3) This is similar to the previous two methods but involves only three grades, namely, $0.3 P, 0.6 P$, and $P$.

The GTM takes tension as the control variable and changes the internal force of a given suspender by tensioning according to the construction sequence. At the same time, the internal forces of the other suspenders change. However, the unstrained length of a suspender changes only when that suspender is tensioned, not when the others are tensioned. Therefore, when the external load is determined, the force adjustment for a suspender corresponds to the change in its unstrained length. Based on this characteristic, the unstrained suspender lengths can be used as control variables for tensioning construction.

In actual tensioning construction of suspenders, the USM and GTM are used in combination, the USGT method, with the USM as the main method and supplemented by the GTM. The USM is used in the initial tensioning process to control the tension precision; in the subsequent graded tensioning, those suspenders that were not tensioned in place before can be adjusted adaptively to achieve reasonable suspender forces.

Based on the above analysis, the suspender forces in each tensioning stage for bridge $\mathrm{A}$ are divided into four grades as listed in Table 2, while the tensioning sequences are given in Table 3 (suspenders and their associated numbers are shown in Figure 7).

\section{Simulation Calculation Results for Bridge $\mathbf{A}$}

From analyzing the whole bridge when in the suspender tensioning stages (as in Figure 8), the main cable vertical displacements are shown in Figure 9. It shows that, in different tensioning stages, the main cable displacement exhibits obvious nonlinear characteristics.

The stiffening girder is made of Q345qE steel, with its design value of compressive/tensile strength $275 \mathrm{MPa}$. Stresses of the stiffening beam and towers are shown in Figure 10. The maximum stress of the stiffening girder in the suspension tensioning stage is $14.5 \mathrm{MPa}$, within the allowable range.

The cables are made of parallel wires, with their standard strength $1770 \mathrm{MPa}$. When in the construction stage of tensioning suspenders, the maximum stress of the cable is 47.95 $\mathrm{MPa}$, within the safety range.

As the suspenders are tensioned, the calculation results of the analysis model show that the tower bottom bending moment remains relatively small. Therefore, by tensioning suspenders of different spans together, the tower top longitudinal displacement and the tower bottom bending moment remain secure. However, suspenders will interact because they are tensioned together, and this aspect requires further discussion in future work. 
TABLe 2: Suspender force at each tensioning stage (unit: $\mathrm{kN}$ ).

\begin{tabular}{|c|c|c|c|c|c|}
\hline \multicolumn{2}{|c|}{ Suspender numbers } & Stage 1 & Stage 2 & Stage 3 & Stage 4 \\
\hline 55 & 160 & 418.75 & 837.50 & 1256.25 & 1675.00 \\
\hline 56 & 161 & 404.22 & 808.44 & 1212.66 & 1616.88 \\
\hline 57 & 162 & 391.09 & 782.18 & 1173.27 & 1564.36 \\
\hline 58 & 163 & 391.22 & 782.44 & 1173.66 & 1564.88 \\
\hline 59 & 164 & 391.84 & 783.68 & 1175.52 & 1567.36 \\
\hline 60 & 165 & 392.50 & 785.00 & 1177.5 & 1570.00 \\
\hline 61 & 166 & 393.39 & 786.78 & 1180.17 & 1573.56 \\
\hline 62 & 167 & 396.14 & 792.28 & 1188.42 & 1584.56 \\
\hline 63 & 168 & 410.94 & 821.88 & 1232.82 & 1643.76 \\
\hline 64 & 169 & 934.96 & 1869.92 & 2804.88 & 3739.84 \\
\hline 65 & 170 & 980.48 & 1960.96 & 2941.44 & 3921.92 \\
\hline 66 & 171 & 433.24 & 866.48 & 1299.72 & 1732.96 \\
\hline 67 & 172 & 416.82 & 833.64 & 1250.46 & 1667.28 \\
\hline 68 & 173 & 413.67 & 827.34 & 1241.01 & 1654.68 \\
\hline 69 & 174 & 412.48 & 824.96 & 1237.44 & 1649.92 \\
\hline 70 & 175 & 411.50 & 823.00 & 1234.50 & 1646.00 \\
\hline 71 & 176 & 410.58 & 821.16 & 1231.74 & 1642.32 \\
\hline 72 & 177 & 409.72 & 819.44 & 1229.16 & 1638.88 \\
\hline 73 & 178 & 408.93 & 817.86 & 1226.79 & 1635.72 \\
\hline 74 & 179 & 408.21 & 816.42 & 1224.63 & 1632.84 \\
\hline 75 & 180 & 407.55 & 815.10 & 1222.65 & 1630.20 \\
\hline 76 & 181 & 406.95 & 813.90 & 1220.85 & 1627.80 \\
\hline 85 & 190 & 407.66 & 815.32 & 1222.98 & 1630.64 \\
\hline 86 & 191 & 408.33 & 816.66 & 1224.99 & 1633.32 \\
\hline 87 & 192 & 409.06 & 818.12 & 1227.18 & 1636.24 \\
\hline 88 & 193 & 409.85 & 819.70 & 1229.55 & 1639.40 \\
\hline 89 & 194 & 410.71 & 821.42 & 1232.13 & 1642.84 \\
\hline 90 & 195 & 411.63 & 823.26 & 1234.89 & 1646.52 \\
\hline 91 & 196 & 412.60 & 825.2 & 1237.80 & 1650.40 \\
\hline 92 & 197 & 413.68 & 827.36 & 1241.04 & 1654.72 \\
\hline 93 & 198 & 416.29 & 832.58 & 1248.87 & 1665.16 \\
\hline 94 & 199 & 430.91 & 861.82 & 1292.73 & 1723.64 \\
\hline 95 & 200 & 974.77 & 1949.54 & 2924.31 & 3899.08 \\
\hline 96 & 201 & 934.96 & 1869.92 & 2804.88 & 3739.84 \\
\hline 97 & 202 & 410.94 & 821.88 & 1232.82 & 1643.76 \\
\hline 98 & 203 & 396.14 & 792.28 & 1188.42 & 1584.56 \\
\hline 99 & 204 & 393.39 & 786.78 & 1180.17 & 1573.56 \\
\hline 100 & 205 & 392.50 & 785.00 & 1177.50 & 1570.00 \\
\hline 101 & 206 & 391.84 & 783.68 & 1175.52 & 1567.36 \\
\hline 102 & 207 & 391.22 & 782.44 & 1173.66 & 1564.88 \\
\hline 103 & 208 & 391.09 & 782.18 & 1173.27 & 1564.36 \\
\hline 104 & 209 & 404.22 & 808.44 & 1212.66 & 1616.88 \\
\hline 105 & 210 & 418.75 & 837.50 & 1256.25 & 1675.00 \\
\hline
\end{tabular}

TABle 3: Tensioning sequences.

\begin{tabular}{lc}
\hline $\begin{array}{l}\text { Tensioning } \\
\text { step }\end{array}$ & Suspender numbers \\
\hline 1 & $64,65,95,96,169,170,200,201$ \\
2 & $63,66,94,97,168,171,199,202$ \\
3 & $62,67,93,98,167,172,198,203$ \\
4 & $61,68,92,99,166,173,197,204$ \\
5 & $60,69,91,100,165,174,196,205$ \\
6 & $59,70,90,101,164,175,195,206,75,180,85,190$ \\
7 & $58,71,89,102,163,176,194,207,76,181,84,189$ \\
8 & $57,72,88,103,162,177,193,208,77,182,83$, \\
9 & 188 \\
10 & $56,73,87,104,161,178,192,209,78,183,82,187$ \\
11 & $55,74,86,105,160,179,191,210,79,184,81,186$ \\
\hline
\end{tabular}

\section{Simulation Calculation Results for Stage 1}

Each stage is divided into several steps, in which different suspenders are tensioned according to the tensioning sequences in Table 3. The vertical displacement change of the main cable for each step in tensioning stage 1 is shown in Figure 11. In suspender tension stages 2-4, the internal forces and displacements of the components at each step have the same regularity as the corresponding values in stage 1.

Several suspenders experience force relaxation during previous several steps in stage 1 . In the final six tensioning steps, the tension response values are more reasonable. The force relaxation effect of the suspenders, the main cable deflection, and the structure performance all improve. 


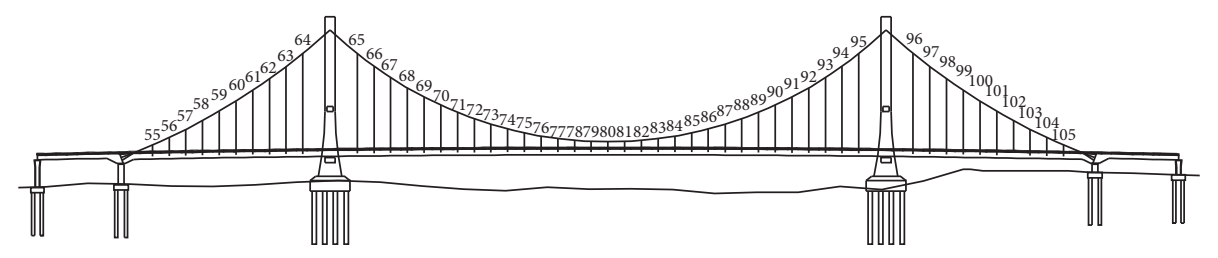

FIGURE 7: Suspenders and their associated numbers.

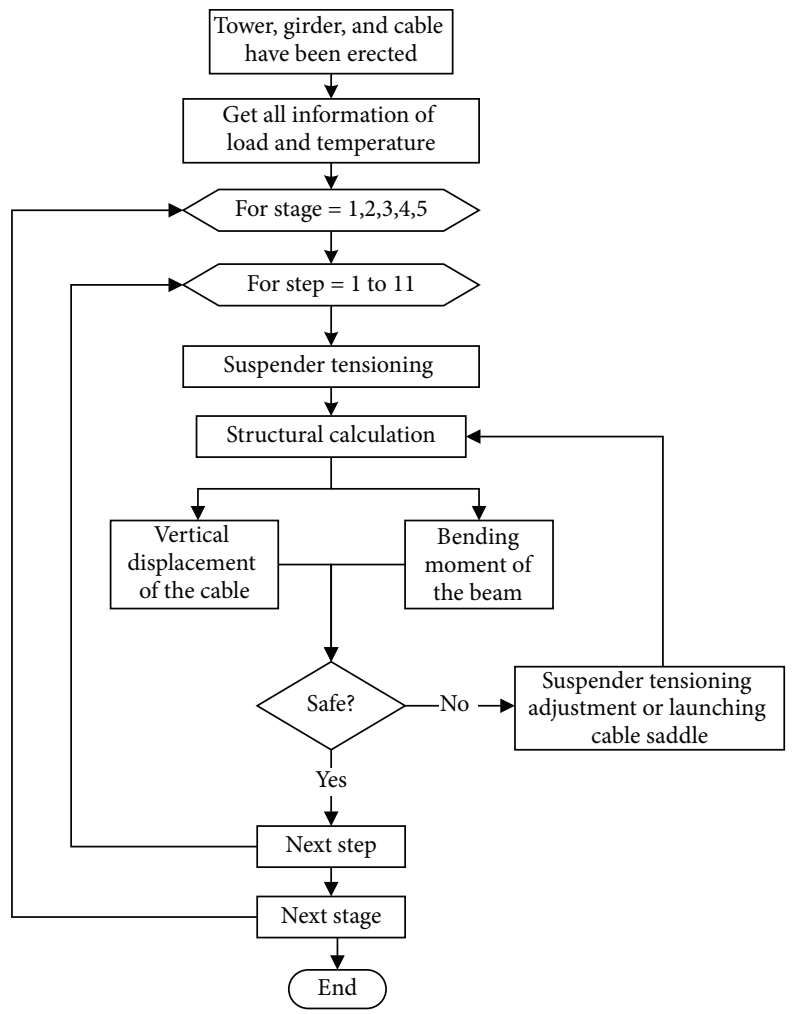

FIGURE 8: Analysis flowchart of suspender tensioning for the self-anchored suspension bridge.

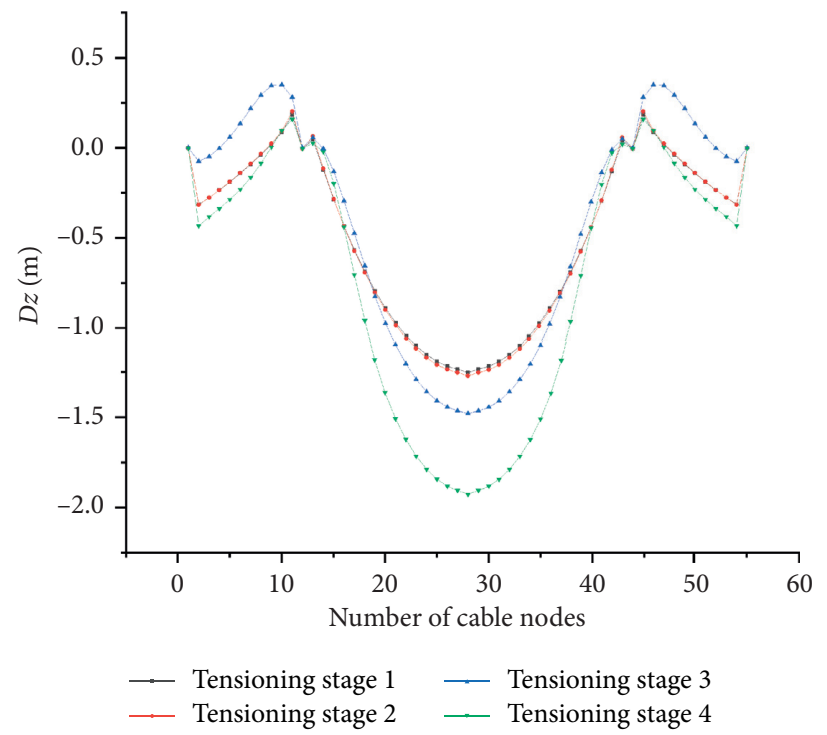

Figure 9: Vertical displacement change of the main cable for each stage. 


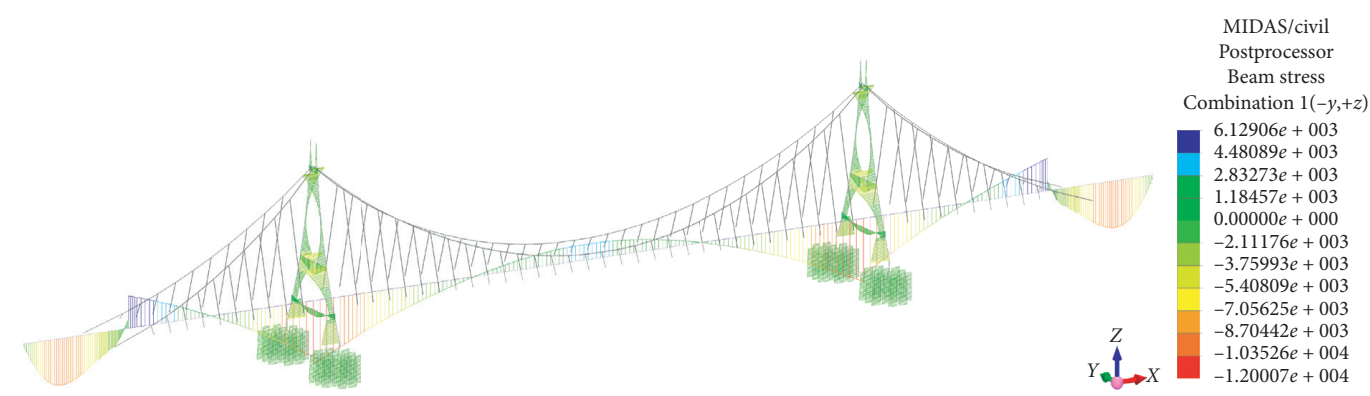

(a)

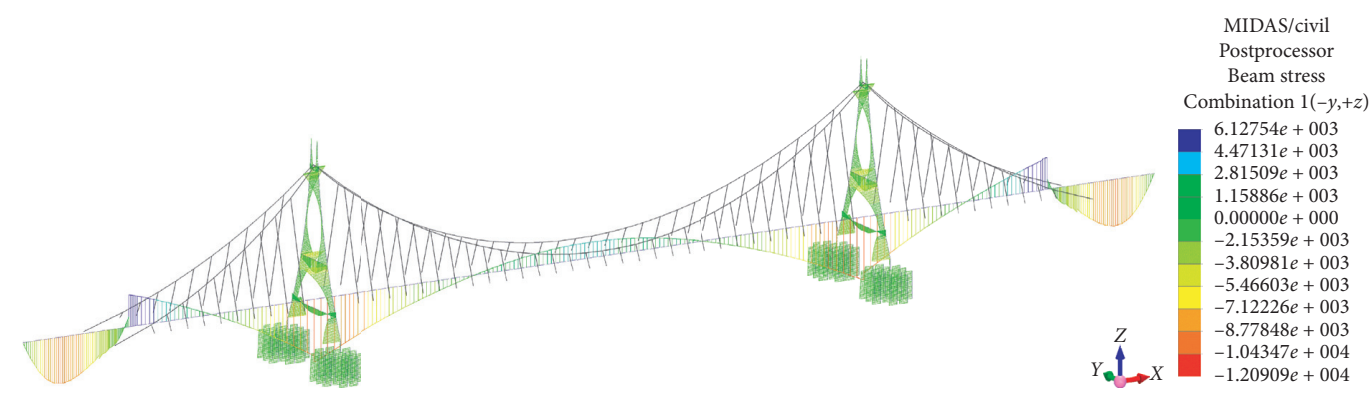

(b)

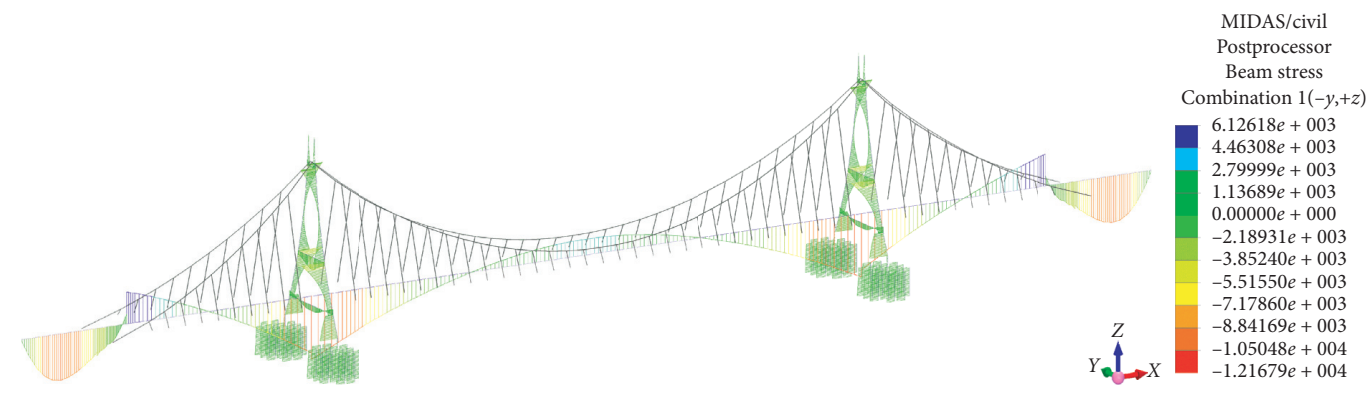

(c)

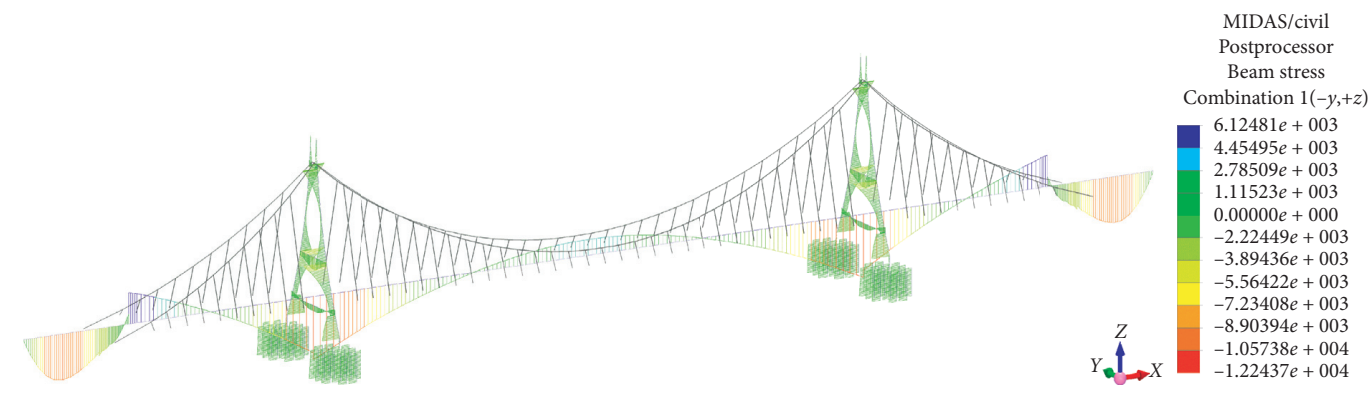

(d)

Figure 10: Bending moment change of the main beam. (a) Tensioning stage 1. (b) Tensioning stage 2. (c) Tensioning stage 3. (d) Tensioning stage 4 .

When the tower top experiences a large longitudinal displacement, the tower bottom experiences a large bending moment response, as does the whole tower. Therefore, to prevent the bending moment from exceeding its limit, the tower must have sufficient bending resistance. For the suspenders of an SASB, a structural analysis chart (as in Figure 5) can be used to adjust their tension. In the model, the corresponding values can be adjusted by the suspender tensioning sequence. Otherwise, the jack method can be used to eliminate the displacement of the tower top, thereby reducing the bending moment in the tower.

In general, it is expected that the horizontal components of main cable forces on both sides of a tower are balanced so that the tower top experiences little longitudinal displacement. Tensioning a suspender changes the forces of the adjacent suspenders in the same span and the forces of suspenders in the adjacent spans. Continuous tensioning increases the influence range of each suspender. 


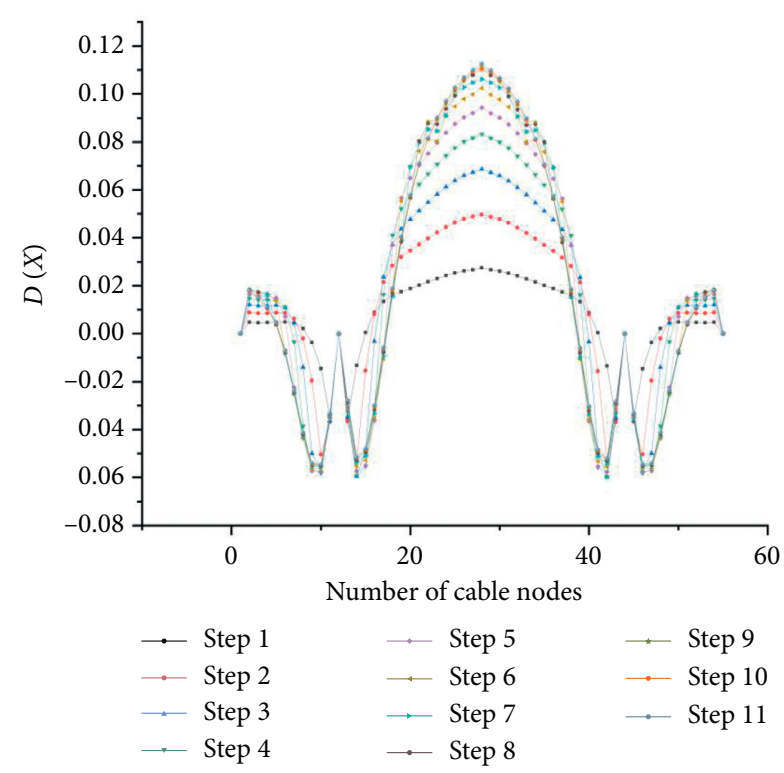

FIGURE 11: Vertical displacement change of the main cable for each step in tensioning stage 1.

\section{Conclusions}

Herein, the USGT method was introduced conceptually and was used for suspender tensioning in the construction of an SASB. The conclusions of this study are summarized as follows.

During suspender tensioning, the stiffening girder experiences little change in its bending moment. Symmetrical tensioning is used here to reduce the tower bending moment and displacement. Also, symmetrical tensioning can simplify the construction process and reduce the construction time.

When the tensioning machine permits, the tensioning sequence of suspenders is symmetrical, tensioning from the main towers to the midspan and the anchor positions. This not only reduces the influence of unbalanced forces on the selfbalance system but also reduces the length or number of extension suspenders and the phenomenon of suspender force relaxation, thereby accelerating the construction progress.

Using the USGT method reduces the number of launching saddles and restricts the displacements and internal forces to only small variations within their corresponding ranges. Different suspender tensioning sequences and grading may affect the forces acting on an SASB. During the construction process, a reasonable suspender tensioning sequence and grading method should be selected according to the actual situation.

\section{Data Availability}

All the data, models, and codes generated or used during this study appear in the submitted article. Some or all data, models, or codes that support the findings of this study are available from the corresponding author upon reasonable request.

\section{Conflicts of Interest}

The authors declare that they have no conflicts of interest.

\section{Acknowledgments}

This research was supported by the Mountain Bridge and Materials Engineering Research Center of Ministry of Education (Grant no. QLGCZX-JJ2017-5), the Postgraduate Research and Innovation Foundation of Chongqing Jiaotong University (no. 2020S0023), the Venture and Innovation Support Program for Chongqing Overseas Returnees (Grant no. cx2020117), and the Chongqing Science and Technology Commission (Grant no. cstc2019jcyjmsxmX0624).

\section{References}

[1] B. Atmaca and S. Ates, "Construction stage analysis of threedimensional cable-stayed bridges," Steel \& Composite Structures, vol. 12, no. 5, pp. 413-426, 2012.

[2] B. Atmaca, T. Dede, and M. Grzywinski, "Optimization of cables size and prestressing force for a single pylon cablestayed bridge with Jaya algorithm," Steel and Composite Structures, vol. 34, no. 6, pp. 853-862, 2020.

[3] J. A. Ochsendorf and D. P. Billington, "Self-anchored suspension bridges," Journal of Bridge Engineering, vol. 4, no. 3, pp. 151-156, 1999.

[4] Y.-M. Sun, L.-Z. Zhang, and Z.-L. Li, "Analysis of parameters influencing suspender target cable forces of self-anchored suspension bridge," Bridge Construction, vol. 45, no. 4, pp. 69-74, 2015.

[5] C.-J. Wang, J.-G. Dai, Y. Zang, and H.-Y. Xiao, "Analysis on static stability of self-anchored suspension bridge with steel box girder," Bridge Construction, vol. 49, no. 2, pp. 47-51, 2019.

[6] X. Wang, P. Fei, Y. Dong, and C. Wang, "Accelerated construction of self-anchored suspension bridge using novel tower-girder anchorage technique," Journal of Bridge Engineering, vol. 24, no. 5, 2019.

[7] Y. Yuan and L.-X. Yi, "Design and key techniques of Gutian self-anchored suspension bridge in Wuhan," Bridge Construction, vol. 49 , no. 2 , pp. 80-85, 2019.

[8] H.-K. Kim, M.-J. Lee, and S.-P. Chang, "Determination of hanger installation procedure for a self-anchored suspension bridge," Engineering Structures, vol. 28, no. 7, pp. 959-976, 2006.

[9] H. J. Ke, C. X. Li, Y. P. Zhang, and C. Dong, "System transformation program and control principles of suspender tension for a self-anchored suspension bridge with two towers and large transverse inclination spatial cables," Tumu Gongcheng Xuebao/China Civil Engineering Journal, vol. 43, no. 11, pp. 94-101, 2010.

[10] C. Li, H. Ke, W. Yang, J. He, and H. Li, "Comparative study on the optimal system transformation schemes for Taohuayu selfanchored suspension bridge," Tumu Gongcheng Xuebao/ China Civil Engineering Journal, vol. 47, no. 9, pp. 120-127, 2014.

[11] Y. Sun, H.-P. Zhu, and D. Xu, "New method for shape finding of self-anchored suspension bridges with three-dimensionally curved cables," Journal of Bridge Engineering, vol. 20, no. 2, Article ID 04014063, 2015.

[12] M.-Y. Kim, M.-R. Jung, and M. M. Attard, "Unstrained length-based methods determining an optimized initial shape of 3-dimensional self-anchored suspension bridges," Computers \& Structures, vol. 217, no. 12, pp. 18-35, 2019. 
[13] X. Zhang, H. Tan, R. Xiao, and S. Chai, "Calculation of longitudinal stiffness of mid-tower in multi-span suspension bridges based on catenary equation," Journal of Huazhong University of Science and Technology (Natural Science Edition), vol. 42, no. 10, pp. 124-127, 2014.

[14] H. Tan, S. Yuan, and R. Xiao, "The adjustment of datum strand of long-span suspension bridges," Zhongguo Tiedao Kexuel China Railway Science, vol. 31, no. 1, pp. 38-43, 2010.

[15] H. Tan, Y. Zeng, and S. H. Sun, "Temperature change influence on strands tensile force in anchor-span suspension bridge," in Proceedings of the 2011 International Workshop on Computational Mechanics, Materials and Engineering Applications, CMMEA 2011, Trans Tech Publications, KKunming, China, July 2011.

[16] H. Tan, Y. Zeng, and X. Zhang, "Cable spring effect and its longitudinal restraint stiffness on towers," Proceedings of the Institution of Civil Engineers-Bridge Engineering, vol. 173, no. 2 , pp. 78-85, 2020. 